\title{
Review
}

Tingting Chen, Tongjiang Cai, Qiao Jin* and Jian Ji

\section{Design and fabrication of functional polycaprolactone}

\begin{abstract}
Functional polycaprolactone (PCL) has great potential for applications in biomedical areas. This review summarizes the recent progress in the chemical synthesis of functional PCL. The functional PCL can be synthesized by (a) homopolymerization or copolymerization of functional $\varepsilon$-caprolactone $(\varepsilon-\mathrm{CL}),(b)$ copolymerization of 2-methylene-1-3-dioxepane with functional vinyl monomers, or (c) copolymerization of $\varepsilon$-CL with functional carbonate monomers. This review presents the recent trends in the synthesis of functional PCL and its biomedical applications.
\end{abstract}

Keywords: $\varepsilon$-caprolactone; functional; MDO; PCL; ringopening polymerization.

DOI 10.1515/epoly-2014-0158

Received August 18, 2014; accepted November 9, 2014

\section{Introduction}

Polycaprolactone (PCL) is one of the earliest polymers synthesized by van Natta et al. (1) via ring-opening polymerization (ROP) of $\varepsilon$-caprolactone ( $\varepsilon$-CL) in the early 1930s. As a fossil fuel-based polyester, PCL is well studied because of its excellent physicochemical properties (2-10). PCL is a kind of hydrophobic, semi-crystalline aliphatic linear polyester with a very low glass transition temperature and melting point $\left(-60^{\circ} \mathrm{C}\right)$ as well as a very slow degradation rate (2-4 years depending on the starting molecular weight) (11). In general, the conventional synthesis of PCL is by ROP

\footnotetext{
*Corresponding author: Qiao Jin, MOE Key Laboratory of Macromolecule Synthesis and Functionalization of Ministry of Education, Department of Polymer Science and Engineering, Zhejiang University, Hangzhou, 310027, China, Tel.: +86 57187953931, e-mail: jinqiao@zju.edu.cn Tingting Chen, Tongjiang Cai and Jian Ji: MOE Key Laboratory of Macromolecule Synthesis and Functionalization of Ministry of Education, Department of Polymer Science and Engineering, Zhejiang University, Hangzhou, 310027, China
}

of $\varepsilon$-caprolactone using a variety of anionic, cationic and coordination catalysts (12). Another route for the synthesis of PCL is by radical ring-opening polymerization (RROP) of 2-methylene-1-3-dioxepane (MDO) (13). Owing to its biocompatibility, biodegradability and tailorable properties, PCL has been extensively studied in biomedical fields, especially in drug delivery systems and tissue engineering (14-17). Furthermore, PCL has already been approved by the FDA and it has been broadly used in medical products such as sutures, bone screws, tissue engineering scaffolds and drug delivery systems. A number of biomedical devices fabricated with PCL have already been launched in the market [e.g., Maxon (Surgical, USA), SynBiosys (Surmodics Inc., USA), Monocryl (Ethicon Inc., USA), etc.].

However, the lack of functional groups in PCL has limited its potential in the design of new functional polymers with good biocompatibility and biofunctionality. For example, due to its hydrophobic nature and poor wettability, lack of cell attachment and uncontrolled biological interactions occur with PCL-based materials (18). Conjugation of peptide ligands with the RGD (Arg-Gly-Asp) sequence to functionalized PCL can improve cell adhesion, which, in turn, triggers cell growth and proliferation. What is more, the introduction of functional groups into commonly used PCL provides PCL with many possibilities to tune its physicochemical properties such as hydrophilicity and degradation rate, which makes PCL more suitable for biomedical applications (19-21). A number of functional PCLs have been synthesized via homopolymerization of functionalized monomers or copolymerization with other functional monomers. This review article will focus on the recent developments in the syntheses of functionalized PCL and discuss its applications in biomedical areas.

\section{Synthesis of functional PCL by functionalized $\varepsilon-C L$ monomers}

ROP (either in melt or in solution) of $\varepsilon$-CL is an attractive method to synthesize PCL. Many functionalized $\varepsilon$-CL 
derivatives have been reported and are summarized in Figure 1, which can be used to synthesize functional PCL via ROP. The functionalized $\varepsilon$-CL monomers can be derivatized at different positions and with a variety of functional groups.

\subsection{Halogen functionalized $\varepsilon-C L$}

Halogen is a very attractive functional group in organic chemistry. Some $\varepsilon$-CL monomers substituted with halogen have been reported in recent years (27, 28, 31-35). 6-Chloro$\varepsilon$-caprolactone, prepared from 6-chlorocyclohexanone by a Bayer-Villiger oxidation, can be polymerized or copolymerized with $\varepsilon$-CL to produce functional PCLs with pendant chloro groups (32). The chloro groups can be subsequently converted into azido moieties using sodium azide with high efficiency. Various functional PCLs can thereby be prepared via click chemistry using alkyne-derivatized molecules (Figure 2). As an example, rosin-ester functionalized PCL was synthesized by a combination of ROP and click chemistry without sophisticated purification of raw renewable biomass from nature (31). The bulky hydrophenanthrene group of rosin increased the glass-transition temperature of PCL by $>100^{\circ} \mathrm{C}$. Degradability test demonstrated that rosin-ester functionalized PCL could be degraded fast by microbials in nature. Meanwhile, the hydrocarbon nature of rosin structures provided PCLs with excellent hydrophobicity and low water uptake, which were essential to ensure longer shelf life during the use of these materials.

Interestingly, the halogen functionalized $\varepsilon$-CL can be used not only as a monomer for ROP, but also as an initiator for atom transfer radical polymerization (ATRP). Wang et al. (27) synthesized poly( $\varepsilon$-caprolactone-co- $\alpha$-bromo$\varepsilon$-caprolactone) $\mathrm{P}$ (CL-co- $\alpha$-BrCL) by copolymerization of $\varepsilon$-CL and $\alpha$-bromo- $\varepsilon$-caprolactone (4). P(CL-co- $\alpha$-BrCL) was used as the macroinitiator for controlled ATRP of styrene for the synthesis of PCL-graft-polystyrene (27). With the same initiator, thermoresponsive $\operatorname{poly}(\mathrm{N}$-isopropylacrylamide) (PNIPAAm) can be grafted to PCL. The stimuli-responsive and biodegradable PCL-g-PNIPAAm can self-assemble into micelles with a diameter of about $70 \mathrm{~nm}$ (28). Using the same strategy, Guo et al.<smiles>C=CCC1CCCCC1=O</smiles>
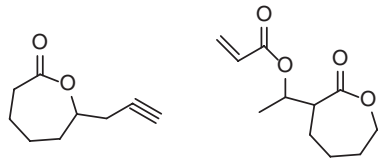

$3(25,26)$

$4(27-28)$<smiles>[B]C1CCCOC1=O</smiles>

$1(22-24)$ $2(23,24)$<smiles>CC(C)(Br)C(=O)OC1CCOC(=O)C1</smiles><smiles>O=C1CCOC(=O)C1</smiles>

9 (36)<smiles>O=C1CCN(C(=O)C(F)(F)F)CC1</smiles>

5 (29)

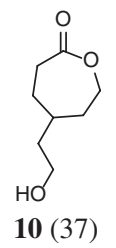

6 (30)

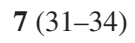

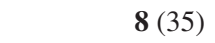<smiles>O=C1CC(Oc2ccccc2)CCO1</smiles><smiles>O=C1OCCCC1I</smiles><smiles>O=C1CCC(OC(=O)C23CO[C@@H](P)OC2C3)CC1</smiles>

13 (29)<smiles>CC1CCC(=O)CC1</smiles>

11 (38)

$$
12 \text { (39) }
$$<smiles>O=C1CCC(NC(=O)OCc2ccccc2)CC1</smiles><smiles>NC1CCCOC1=O</smiles>

19 (43)<smiles>[C+][C@H]1CCOC(=O)C1</smiles>

20 (40)

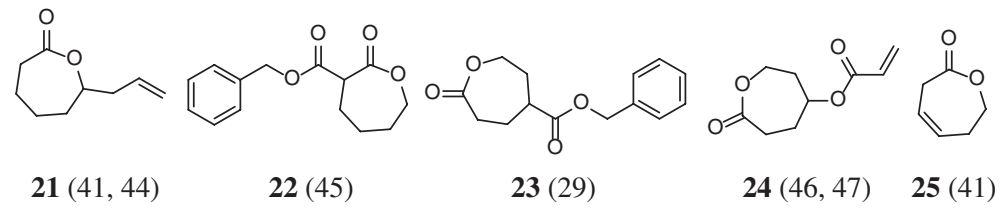

Figure 1 Chemical structures of functionalized $\varepsilon-C L$ monomers. 


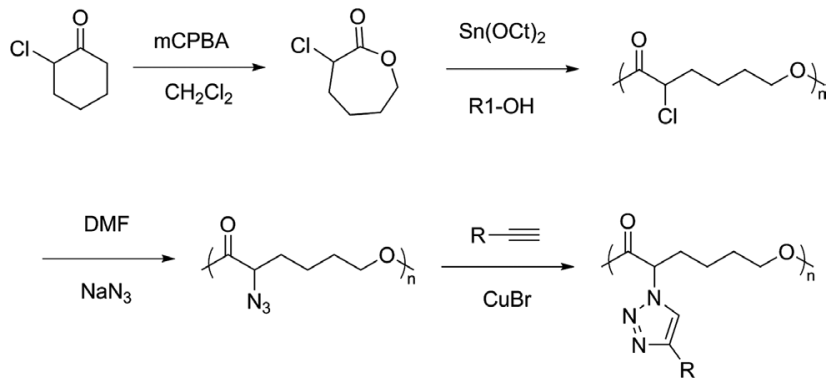

Figure 2 Synthesis of functional PCL from 6-chloro-ع-caprolactone.

(48) synthesized pH-dependent temperature-sensitive PCL-g-PDMAEMA, a kind of degradable, amphiphilic, cationic copolymer (48). With the higher density of positive charge due to the grafted PEDMAEMA short chains on the surface, the self-assembled nanoparticles of PCLg-PDMAEMA exhibit better efficiency for siRNA delivery than the nanoparticles of PCL-b-PDMAEMA both in vitro and in vivo (49). Furthermore, the halogen functionalized $\varepsilon$-CL can be used to construct branched copolymers using ROP and ATRP. Mecerreyes et al. (35) prepared branched copolymers by sequential and concurrent polymerizations of $\gamma$-( $\varepsilon$-caprolactone)-2-bromo-2-dimethylpropionate (8) and 2-hydroxyethyl methacrylate (HEMA) without going through a traditional multistep procedure. The branching density can be simply adjusted by the addition of the appropriate CL and/or HEMA monomers and by the variation of the ratio of the two monomers.

\subsection{Unsaturated $\varepsilon-C L$}

Unsaturated $\varepsilon$-CL is another powerful monomer to synthesize functional PCL. The double bond in PCL can be further functionalized by bromination, epoxidation, or hydrosilylation. Acrylate $\varepsilon$-CL (e.g., $\mathbf{3}$ and $\mathbf{2 4}$ ) is one of the most promising unsaturated $\varepsilon$-CLs since it can be polymerized by two independent mechanisms, i.e., ROP and radical polymerization. Furthermore, it can also conjugate with thiol or amino-functionalized molecules by Michael addition. Mecerreyes et al. (46) reported for the first time a bifunctional acrylate-lactone monomer 4-(acryloyloxy)$\varepsilon$-caprolactone (24) that can be polymerized by ROP and ATRP in a living/controlled way. The obtained polymers had controlled molecular weights and narrow polydispersities $\left(M_{\mathrm{w}} / M_{\mathrm{n}} \sim 1.2\right)$. Unsaturated PCL can be oxidized to epoxy functionalized PCL, which can conjugate with hydroxyl-, thiol-, and amino-functionalized molecules at high reactivity (44). van der Ende et al. (50, 51) synthesized epoxide-functionalized polyesters that were further cross-linked with $2,2^{\prime}$-(ethylenedioxy)bis(ethylamine) to give well-defined multifunctional polyester nanoparticles with a narrow size distribution and a selected nanoscopic size dimension.

The azide-alkyne click chemistry is a powerful tool to achieve the coupling of synthetic polymers with nucleic acid, peptides, proteins, and many other molecules, which can help researchers design precisely controlled macromolecular architectures (52, 53). Alkyne-functionalized PCLs were well developed and used for bioconjugation via azide-alkyne click chemistry. For instance, $\mathrm{Gd}^{3+}$ was conjugated to alkyne-functionalized PCL with controlled $\mathrm{Gd}^{3+}$ grafting density (22). The obtained magnetic resonance imaging-visible PCL provided a safe and efficient magnetic resonance visibility to implantable medical devices. The novel degradable and antibacterial PCL with pendant propargyl groups was successfully prepared by ROP and subsequently grafted with antibacterial hydantoin moieties via click chemistry (24). Such hydantoin-grafted PCL showed excellent antimicrobial activities regarding both Escherichia coli and Bacillus subtilis. With the advantage of alkyne-functionalized PCL, $\beta$-cyclodextrin was conjugated to PCL polymer chain. The $\beta$-cyclodextrin has the shape of a hollow cone, which allows it to include hydrophobic small molecular guests into its cavity. In this manner, many hydrophobic substances become water soluble. Thus the $\beta$-cyclodextrin-modified PCL has a potential for applications in supramolecular chemistry as a carrier for, e.g., drugs or catalysts (23).

\subsection{Other functional $\varepsilon-C L$}

In addition to the aforementioned functionalized $\varepsilon$-CL monomers, there are many other examples of functional $\varepsilon$-CL monomers, as shown in Figure 1.

The polar functional groups, such as hydroxyl, carboxylic acid, and amino groups, are very useful substituents because they can undergo many reactions and increase hydrophilicity. In order to obtain hydroxyl-functionalized PCLs, the use of direct ROP of hydroxyl-substituted $\varepsilon$-CL is not possible since the hydroxyl groups are the initiator of the ROP of $\varepsilon$-CL. Therefore, PCLs with pendant hydroxyl groups are usually prepared by protection of the hydroxyl groups of $\varepsilon$-CL followed by a post polymerization deprotection (Figure 3) $(29,40)$. Trollsas et al. (29) synthesized and polymerized $\gamma$-( $\varepsilon$-caprolactone)-2,2bis(phenyldioxymethyl)propionate (13) and $\gamma$-benzyloxy$\varepsilon$-caprolactone (14). Hydroxyl-functionalized PCL can be obtained by the subsequent removal of the benzyl protection group via catalytic hydrolyzation. In another 


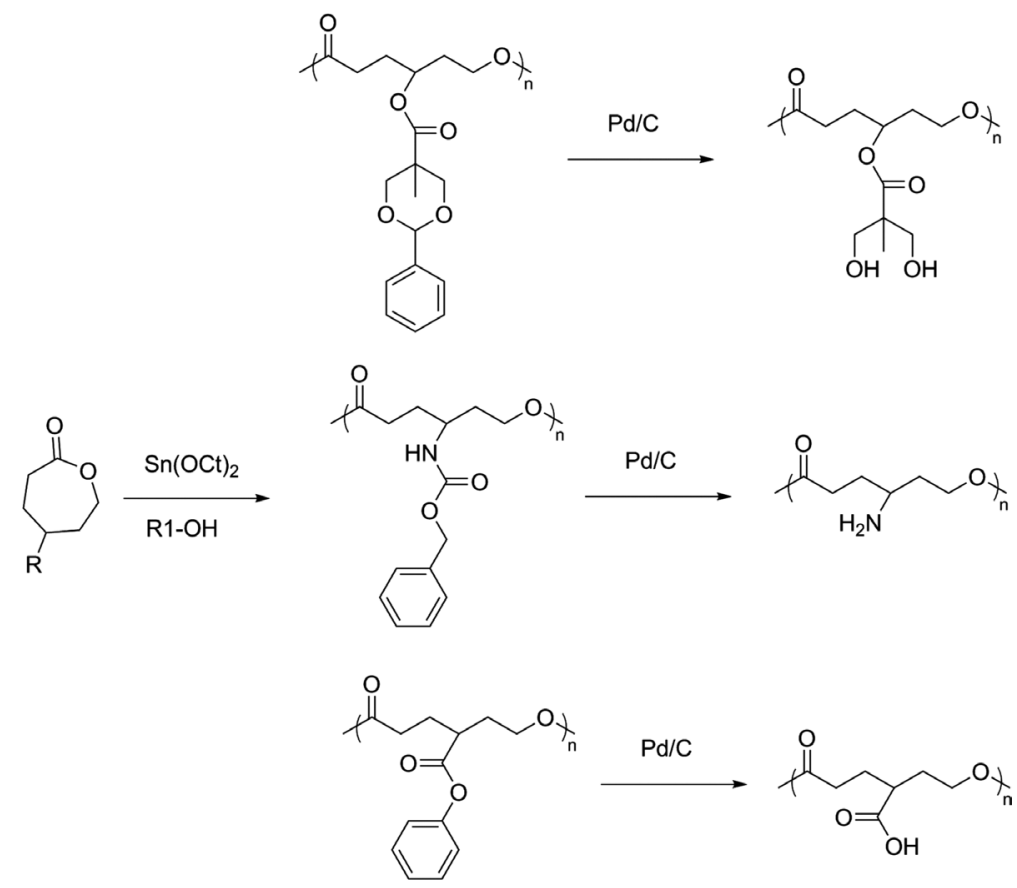

Figure 3 Synthesis of the hydroxyl, carboxylic acid, and amino groups of functionalized PCL.

research, 5-ethylene ketal $\varepsilon$-caprolactone (6) was polymerized in a well-controlled manner using $\mathrm{Al}(\mathrm{OiPr})_{3}$ as the initiator. PCL-bearing hydroxyl groups can be easily prepared by the reduction of the ketone groups into hydroxyl groups (30). The hydroxyl groups can also be protected by a triethylsiloxy group (20), which can be easily hydrolyzed under milder conditions (40).

PCL-bearing amino groups were synthesized by $\varepsilon$-CL monomers containing protected amino groups, $\gamma$-(carbamic acid benzyl ester)- $\varepsilon$-caprolactone $(\gamma \mathrm{CAB \varepsilon CL}$; 18) (42). A series of copolymers [poly(CL-co-CABCL)] were prepared by ROP of $\varepsilon$-CL and $\gamma \mathrm{CAB \varepsilon CL}$ using $\mathrm{Sn}(\mathrm{Oct})_{2}$ as the catalyst. The morphology of the copolymers changed from semicrystalline to amorphous upon increasing the $\gamma \mathrm{CAB \varepsilon CL}$ monomer content. Amino-functionalized PCL can be prepared by hydrogenolysis of poly(CL-co-CABCL) in the presence of $\mathrm{Pd} / \mathrm{C}$. The pendant amino groups were then used for the attachment of biotin to the polymer.

Carboxylic acid group functionalized PCL have also been reported. Trollsas et al. (29) synthesized benzyl $\gamma$-( $\varepsilon$-caprolactone) carboxylate (23) and tert-butyl $\gamma$-( $\varepsilon$-caprolactone) carboxylate (25), which were used to prepare protected PCLs. After the hydrogenolysis in the presence of $\mathrm{Pd} / \mathrm{C}$, the carboxylic acid group functionalized PCL was obtained (29).

In addition, different pendant groups could also be incorporated into PCL to tune the physicochemical properties of the material. For example, the introduction of the moieties of 5-ethylene ketal $\varepsilon$-caprolactone into the PCL segments of the PEG-PCL diblock copolymer could decrease the crystallinity of the polymer, thus raising the solid content of the PEG-PCL self-assembly nanoparticles in water by up to $25 \mathrm{wt} \%$ with excellent storage stability (54). In another research, the triblock copolymer of PEG and modified PCL with cyclic ether pendant groups (PECT) presented a perfect dispersity in water and a more controlled thermal gelation behavior than the PCL-PEG-PCL block copolymer and significantly avoided the pre-quenching treatment that was needed for PCL-PEG-PCL gelation. The transition temperature and gelation behavior could be adjusted by the content of the cyclic ether pendant groups on the PCL segments (55). After the reduction of the ketone groups into hydroxyl groups, the hydroxyl groups on the PCL segment hardly had effect on the crystallinity of PCL because of the hydrogen bond interaction. However, the hydroxyl groups on the PCL segment benefited from the higher loading capacity of doxorubicin (DOX), but slowed down the release rate in vitro (56).

\section{Synthesis of functional PCL by copolymerization of MDO}

As discussed previously, PCL can be synthesized not only by ROP of $\varepsilon$-CL, but also by RROP of MDO. Actually, cyclic 


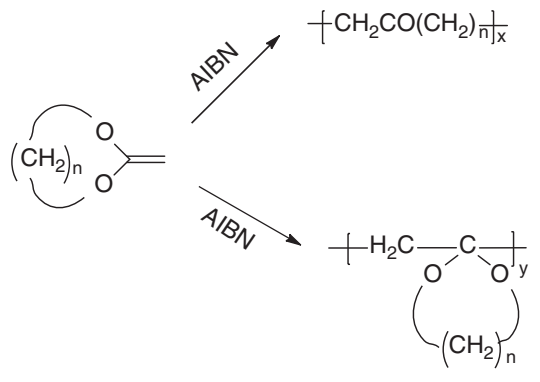

Figure 4 Free-radical polymerization of a cyclic ketene acetal [Reprinted with permission from Ref. (57). Copyright 1997 by the American Chemical Society.]

ketene acetals like MDO can undergo both ring-opening and ring-retaining polymerization when initiated by free radicals, leading to two different structures (Figure 4). The free-radical polymerization of the MDO monomer was reported to proceed with $100 \%$ ring opening to form PCLs. The free radicals proposed in both the initiation and the propagation steps were primary alkyl radicals, which were very reactive and likely to undergo intramolecular hydrogen transfer to form more stable radicals (Figure 5). The resulting PCL would have some branched structures. Therefore it was totally amorphous instead of semicrystalline (57), which was beneficial for increasing the biodegradable rate. More interestingly, this polymerization reaction provides a new possibility to combine ester units with the $\mathrm{C}$-C backbone of vinyl polymers in a random way to generate a new class of biodegradable materials [poly(vinyl-co-ester)s] (Figure 6) (58-64). Therefore, it allows the copolymerization of MDO with different functional vinyl monomers and, as a result, introduces functionality into PCL. It opens a new door to design various functional biodegradable polyesters. The introduction of functional groups into PCL is still a challenge and has been done in many steps by ROP of functional $\varepsilon$-CL monomers. However, it is much easier to get functional PCLs by copolymerization of MDO and functional vinyl monomers.

Hedir et al. (65) synthesized a series of linear and hyperbranched copolymers of MDO with functional vinyl monomers to deliver a range of functional, degradable polymers by reversible deactivation radical polymerization. The copolymer showed a predictable molar mass and a low dispersity value while also featuring side-chain functionality (65). MDO can be copolymerized with $\mathrm{N}, \mathrm{N}$ dimethylaminoethyl methacrylate (DMAEMA) using PEO as the initiator (Figure 7) (66). The copolymer showed little cytotoxicity and full degradability, and thus presented as a promising DNA transfection agent.

MDO-based thermosensitive PCL hydrogels were reported recently for cardiac tissue engineering (67). The copolymer was synthesized by RROP of MDO, NIPAAm,

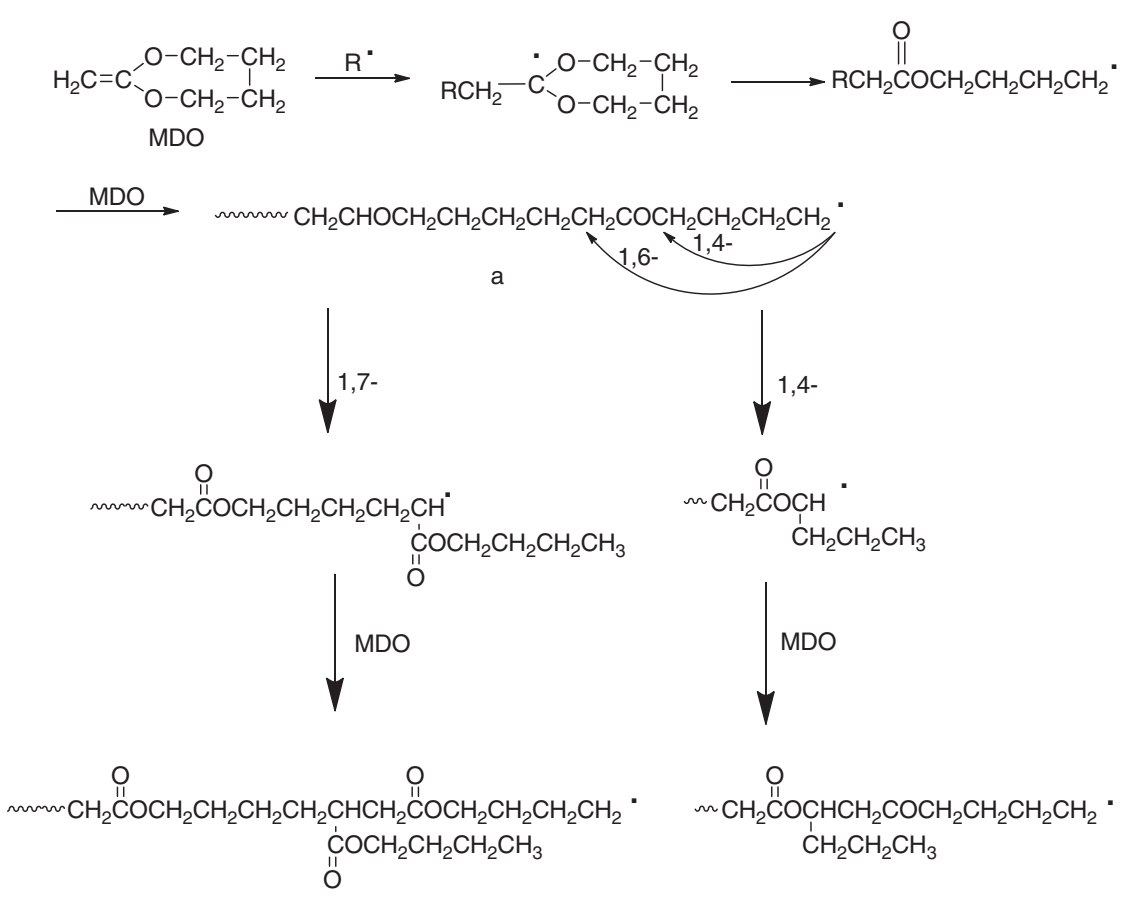

Figure 5 Branch formation in the free-radical polymerization of 2-methylene-1,3-dioxepane. [Reprinted with permission from Ref. (57). Copyright 1997 by the American Chemical Society.] 


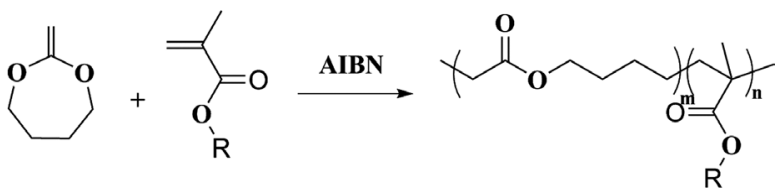

Figure 6 Copolymerization of MDO with functional vinyl monomers.

methacrylic acid, and methoxy(polyethylene glycol) methacrylate (mPEGMA). This PNIPAM-based copolymer underwent spontaneous sol-gel transition at body temperature. Thus it was especially attractive as an injectable biomaterial. The electro-active tetraaniline was then conjugated to the copolymer, which endowed these copolymers with desirable electrical properties and antioxidant activities. Both in vitro and in vivo results demonstrated that the electro-active hydrogel can be used as a promising injectable biomaterial for cardiac tissue engineering. Undin et al. $(68,69)$ synthesized amorphous and functional polyesters through the copolymerization of MDO and glycidyl methacrylate (GMA). The resulting epoxyfunctionalized polyester was further modified by covalent immobilization of heparin to enhance the osteogenic differentiation of mesenchymal stem cells $(68,69)$.

MDO-based functional PCL can be used as a drug nanocarrier. A series of biodegradable, biocompatible, and cross-linkable copolymers $\mathrm{P}(\mathrm{MDO}-\mathrm{co}-$ PEGMA-co-CMA) with different compositions were synthesized by copolymerization of MDO, MPEGMA, and 7-(2-methacryloyloxyethoxy)-4-methylcoumarin methacrylate (CMA) (70). The amphiphilic P(MDO-coPEGMA-co-CMA) can self-assemble into micelles with different sizes. Because of the coumarin side groups in the micellar core, the micelles can be cross-linked upon exposure to long-wavelength UV light ( $365 \mathrm{~nm})$. The biodegradable micelles were then applied for the delivery of the anticancer drug DOX. DOX can be successfully encapsulated into the micellar core and released at a very low velocity. After cross-linking, DOX was released from the micelles much slower than from the uncross-linked micelles. In order to maximize the therapeutic effect, stimuli-responsive drug nanocarriers were developed to realize smart drug release when the micelles arrived at the site of action. Redox-responsive biodegradable

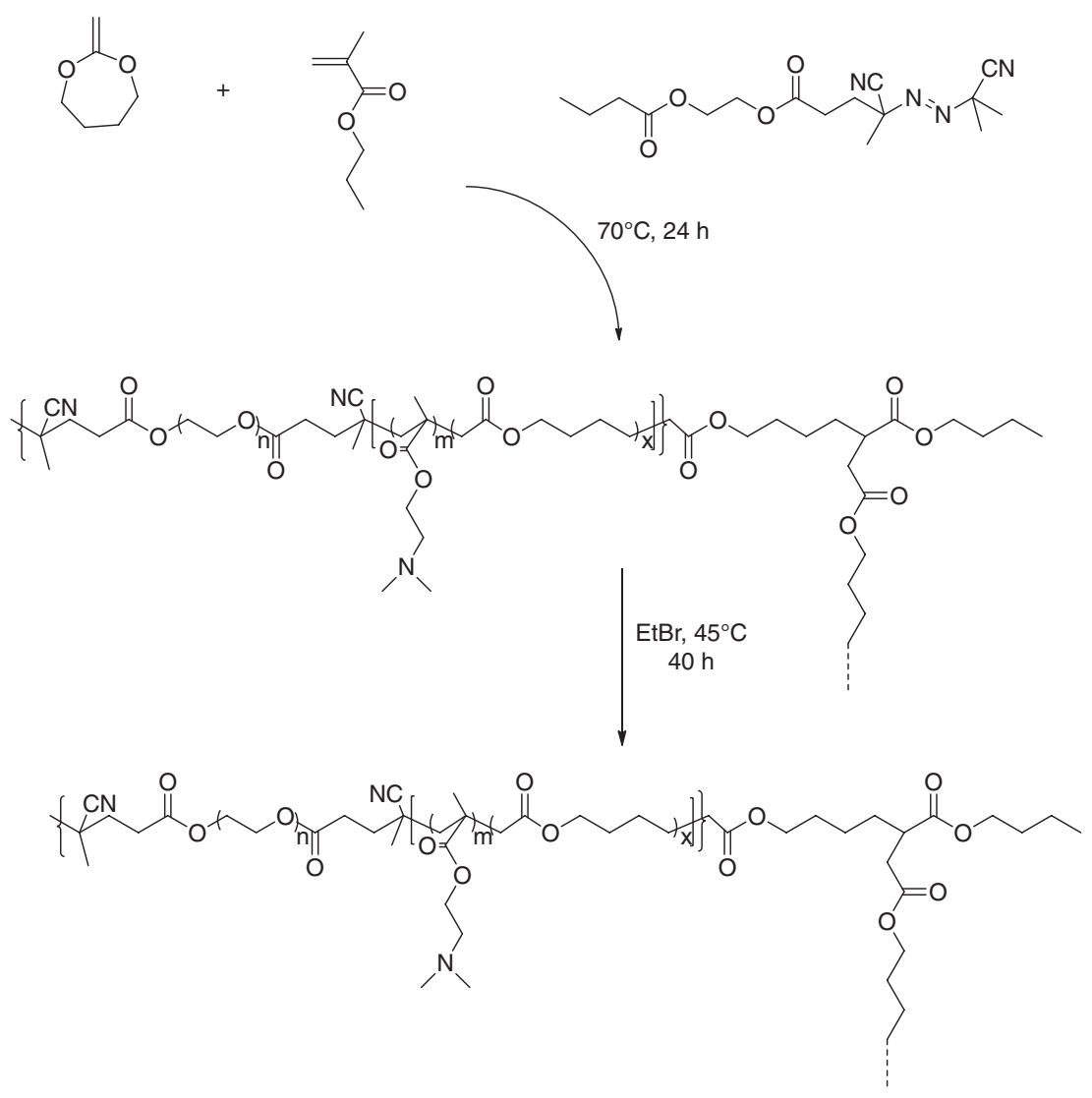

Figure 7 Copolymerization of MDO and DMAEMA using PEO as the initiator and subsequent quaternization using bromoethane. [Reprinted with permission from Ref. (66). Copyright 2013 by Wiley InterScience.] 
drug nanocarriers were hence designed by copolymerization of MDO with pyridyldisulfide ethylmethacrylate (PDSMA), which were developed as novel platforms for rapid redox-responsive drug release in the presence of intracellular glutathione (GSH) (71). As expected, in vitro drug release showed that the release of DOX can be rapidly accelerated in the presence of $10 \mathrm{mmol} / \mathrm{l}$ of $\mathrm{GSH}$, which was analogous to the intracellular reductive microenvironment. Meanwhile, the PDSMA-containing copolymer can be used to covalently conjugate Mal-DOX, which contains a $\mathrm{pH}$-sensitive hydrazone bond between DOX and the maleimide group (72). Biodegradable $\mathrm{pH}-$ sensitive polymeric prodrugs were therefore constructed for intracellular drug delivery.

The biodegradability of different poly(vinyl-co-ester) $\mathrm{s}$ has also evoked great interest recently. Actually, the biodegradable properties of these copolymers are highly tunable by varying the species of vinyl monomers and the composition of the copolymers. Albertsson et al. (2) synthesized a series of 2-methylene-1,3-dioxepane/glycidyl methacrylate-based (MDO/GMA) copolymers with different feed ratios and immersed them into a phosphate buffer solution at $\mathrm{pH} 7.4$ and in deionized water at $37^{\circ} \mathrm{C}$ for up to 133 days. The following degradation properties were evaluated: molecular weight changes, mass loss, $\mathrm{pH}$ and degradation products. The results of the experiments suggested that, by increasing the amount of GMA functional groups in the material, the degradation rate and the amount of acidic degradation products released from the material were decreased. A possible reason could be the existence of some steric hindrance by the bulky GMA chain, which hampers the hydrolysis of the ester side groups (68).

\section{Synthesis of functional PCL by copolymerization with functional carbonate monomers}

Functional PCL can be obtained by copolymerization of $\varepsilon$-CL with functional carbonate monomers as well. Chen et al. (73) synthesized functional copolymers by copolymerization of $\varepsilon$-CL and (meth)acryloyl carbonate (P(CLco-AC)). The (meth)acryloyl groups in the polymer chain were amenable to thiol-ene click chemistry with various thiol-containing molecules such as 2-mercaptoethanol, 3-mercaptopropanoic acid, cysteamine, cysteine, and arginine-glycine-aspartic acid-cysteine (RGDC) peptide under mild conditions, to provide biodegradable materials with vastly different functionalities and properties (Figure 8). The initiator of reversible addition-fragmentation chain transfer (RAFT) polymerization, 4-cyanopentanoic acid dithionaphthalenoate, was conjugated to P(CL-Co-AC) by thiol-ene click chemistry and carbodiimide chemistry (74). PCL-g-PHEMA can therefore be synthesized by RAFT of HEMA. The biodegradable PCL-g-PHEMA can self-assemble to micelles, which were used as superior nanocarriers for "smart" doxorubicin release. A pyridyl disulfide-functionalized cyclic carbonate (PDSC) monomer was synthesized by the same group (75). P(CL-PDSC) was prepared by ring-opening copolymerization of $\varepsilon$-CL and PDSC with controlled molecular weights and functionalities. The exchange reaction between PDS-functionalized PCL and thiolated poly(ethylene glycol) (PEG-SH) afforded PCL-gSS-PEG graft copolymers in high yields. The PCL-g-SS-PEG copolymer self-assembled into micelles with a diameter of 110-120 nm. DOX was loaded into PCL-g-SSPEG micelles

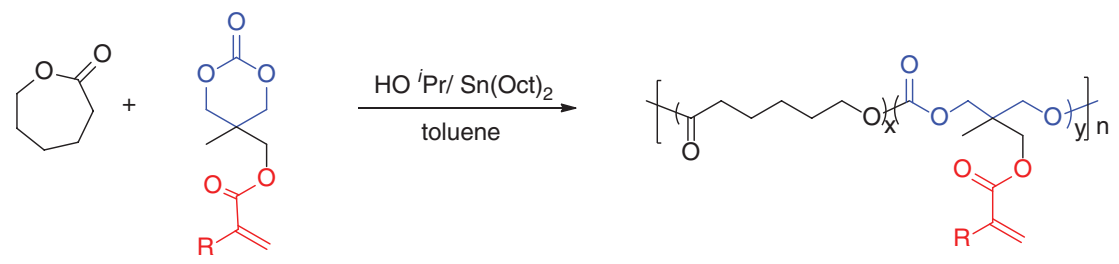

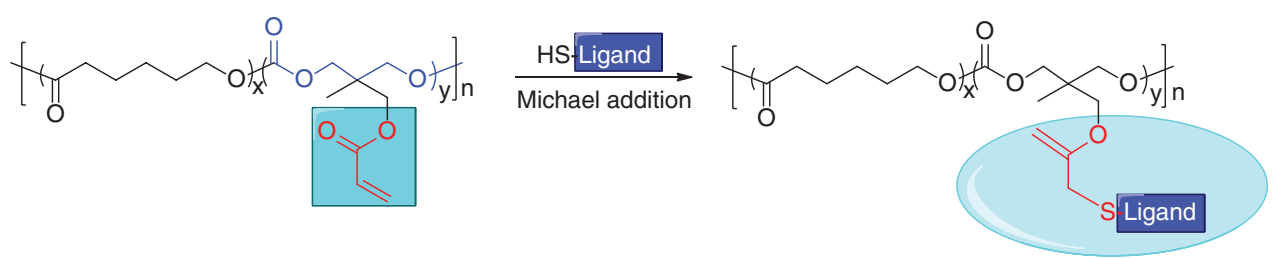

Figure 8 Ring-opening copolymerization of $\varepsilon$ - $C L$ with (meth)acryloyl carbonate and subsequent thiol-ene click chemistry with thiol-containing molecules. [Reprinted with permission from Ref. (73). Copyright 2010 by the American Chemical Society.] 
with a decent drug loading content of 10.1 wt $\%$. Notably, in vitro release studies revealed that ca. $82.1 \%$ DOX was released in $12 \mathrm{~h}$ under a reductive environment analogous to that of the intracellular compartments, whereas only ca. $17.5 \%$ DOX was released in $24 \mathrm{~h}$ under non-reductive conditions.

\section{Other methods to synthesize functional PCL}

In addition to the aforementioned methods, there are many other approaches to synthesize functional PCL.

PCL modified with RAFT/ATRP initiators or acrylate units at the end of the chain was usually used for further polymerization with vinyl monomers, so as to obtain functional PCLs. Ratner et al. (76) synthesized biodegradable poly( $N$-isopropyl acrylamide) (poly-NIPAM) hydrogels with controlled molecular weight of the parent polymer and its degradation products by atom transfer radical polymerization in the presence of a polycaprolactonebased di-chlorinated macroinitiator and polycaprolactone dimethacrylate. This polymer has potential applications in fabricating degradable, thermoresponsive scaffolds for tissue engineering.

Moreover, functional PCL could also be synthesized by utilizing functional initiators for ring-opening polymerization of caprolactone. For instance, linear poly(hexamethylene guanidine) (PHMG) hydrochloride with primary amino $\left(-\mathrm{NH}_{2}\right)$ end groups could act as a macroinitiator for caprolactone polymerization, which leads to the blocking of copolymers that combine the antibacterial properties of PHMG with the degradability provided by PCL (77).

\section{Conclusions}

The synthesis of functionalized PCL has attracted considerable attention due to its unique applications in biomedical areas. The introduction of functional groups is especially important since it can control the physical and chemical properties of the resultant functional PCL, such as crystallinity, hydrophilicity, $T_{\mathrm{g}}$, or degradation rate. In this review, the recent approaches to synthesize functional PCL and its biomedical applications are summarized. PCL bearing various functional groups with well-defined characteristics can be synthesized by homopolymerization of functional $\varepsilon$-CL, copolymerization of MDO with functional vinyl monomers, or copolymerization of $\varepsilon$-CL with functional carbonate monomers.

Although functional PCL is potentially biocompatible and biodegradable, only a limited number of studies regarding the applications of functional PCL have been published. However, the future of functional PCL must be very bright since there is an ever-increasing demand for well-characterized and well-defined functionalized materials for biomedical applications. There is still much potential for the development of novel functional PCL. In particular, it will be very helpful to synthesize functional monomers in an easy and mild way by using renewable resources.

Acknowledgments: Financial support was provided by the National Natural Science Foundation of China (nos. 51333005, 51103126, and 51303154), Research Fund for the Doctoral Program of Higher Education of China (no. 20130101120177), and the Scientific Research Fund of Zhejiang Provincial Education Department (no. Y201326564).

\section{References}

1. van Natta FJ, Hill JW, Carothers WH. Studies of polymerization and ring formation. XXIII.1 $\varepsilon$-Caprolactone and its polymers. J Am Chem Soc. 1934;56(2):455-7.

2. Albertsson AC, Varma IK. Aliphatic polyesters: Synthesis, properties and applications. Adv Polym Sci. 2002;157:1-40.

3. Marta P, Aleksandra A, Katarzyna W. Preparation of ciprofloxacinencapsulated poly- $\varepsilon$-caprolactone microcapsules by the solvent evaporation technique. e-Polymers 2013;13(1):319-30.

4. Leroux F, Montembault V, Pascual S, Guerin W, Guillaumeb SM, Fontaine L. Synthesis and polymerization of cyclobutenyl-functionalized polylactide and polycaprolactone: a consecutive ROP/ ROMP route towards poly(1,4-butadiene)-g-polyesters. Polym Chem. 2014;5:3476-86.

5. Cipitria A, Skelton A, Dargaville TR, Dalton PD, Hutmacher DW. Design, fabrication and characterization of PCL electrospun scaffolds - a review. J Mater Chem. 2011;21:9419-53.

6. Pounder RJ, Dove AP. Towards poly(ester) nanoparticles: recent advances in the synthesis of functional poly(ester)s by ring-opening polymerization. Polym Chem. 2010;1(3):260-71.

7. Li Q, Wang ZH, Zhao Q, Wang LY, Wang SF, Kong DL. Tissue engineering scaffold electrospun from poly( $\varepsilon$-caprolactone)b-poly(sulfobetaine methacrylate) block copolymers with improved hydrophilicity and good cytocompatibility. e-Polymers 2012;12(1):584-95.

8. Maafi EM, Malek F, Tighzert L, Laoutid F, Dubois P. Synthesis and thermal properties of new copolyesters based on polycaprolactone. e-Polymers 2012;12(1):304-16.

9. Lecomte P, Riva R, Jerome C, Jerome R. Macromolecular engineering of biodegradable polyesters by ring-opening polymerization and 'click' chemistry. Macromol Rapid Commun. 2008;29(12-13):982-97. 
10. Jerome C, Lecomte P. Recent advances in the synthesis of aliphatic polyesters by ring-opening polymerization. Adv Drug Deliv Rev. 2008;60(9):1056-76.

11. Woodruff MA, Hutmacher DW. The return of a forgotten polymer - Polycaprolactone in the 21st century. Prog Polym Sci. 2010;35:1217-56.

12. Pitt CG. Polycaprolactone and its copolymers. In: Chasin M, Langer R, editors. Biodegradable polymers as drug delivery systems. New York: Marcel Dekker; 1990. 71-120 pp.

13. Bailey WJ, Chen PY, Chiao WB, Endo T, Sidney L, Yamamoto N, Yamazaki N, Yonezawa K. Contemporary topics. Polym Sci. 1979;3:29.

14. Dash TK, Konkimalla VB. Polymeric modification and its implication in drug delivery: poly- $\varepsilon$-caprolactone $(\mathrm{PCL})$ as a model polymer. Mol Pharm. 2012;9(9):2365-79.

15. Dash TK, Konkimalla VB. Poly- $\varepsilon$-caprolactone based formulations for drug delivery and tissue engineering: a review. J Control Rel. 2012;158:15-33.

16. Coulembier O, Degee P, Hedrick JL, Dubois P. From controlled ring-opening polymerization to biodegradable aliphatic polyester: especially poly( $\beta$-malic acid) derivatives. Prog Polym Sci. 2006;31:723-47.

17. Lou XD, Detrembleur C, Jerome R. Novel aliphatic polyesters based on functional cyclic (di)esters. Macromol Rapid Commun. 2003;24(2):161-72.

18. Place ES, George JH, Williams CK, Stevens MM. Synthetic polymer scaffolds for tissue engineering. Chem Soc Rev. 2009;38:1139-51.

19. Xiao Y, Yuan M, Zhang J, Yan JL, Lang MD. Functional Poly ( $\varepsilon$-caprolactone) based materials: preparation, self-assembly and application in drug delivery. Curr Top Med Chem. 2014;14(6):781-818.

20. Seyednejad H, Ghassemi AH, van Nostrum CF, Vermonden T, Hennink WE. Functional aliphatic polyesters for biomedical and pharmaceutical applications. J Control Rel. 2011;152:168-76.

21. Williams CK. Synthesis of functionalized biodegradable polyesters. Chem Soc Rev. 2007;36:1573-80.

22. Habnouni SE, Nottelet B, Darcos V, Porsio B, Lemaire L, Franconi F, Garric X, Coudane J. MRI-Visible poly( $\varepsilon$-caprolactone) with controlled contrast agent ratios for enhanced visualization in temporary imaging applications. Biomacromolecules 2013;14:3626-34.

23. Jazkewitsch O, Mondrzyk A, Staffel R, Ritter H. Cyclodextrinmodified polyesters from lactones and from Bacteria: an approach to new drug carrier systems. Macromolecules 2011;44:1365-71.

24. Tan LC, Maji S, Mattheis C, Chen YW, Agarwal S. Antimicrobial hydantoin-grafted poly( $\varepsilon$-caprolactone) by ring-opening polymerization and click chemistry. Macromol Biosci. 2012;12:1721-30.

25. Li HY, Jerome R, Lecomte P. Synthesis of tadpole-shaped copolyesters based on living macrocyclic poly( $\varepsilon$-caprolactone). Polymer 2006;47:8406-13.

26. Li HY, Debuigne A, Jerome R, Lecomte P. Synthesis of macrocyclic poly( $\varepsilon$-caprolactone) by intramolecular cross-linking of unsaturated end groups of chains precyclic by the initiation. Angew Chem Int Ed. 2006;45:2264-7.

27. Wang GJ, Shia Y, Fu ZF, Yang WT, Huang QG, Zhang YD. Controlled synthesis of poly( $\varepsilon$-caprolactone)-graft-polystyrene by atom transfer radical polymerization with poly( $\varepsilon$-caprolactone- co- $\alpha$-bromo- $\varepsilon$-caprolactone) copolymer as macroinitiator.

Polymer 2005;46:10601-6.

28. Massoumi B, Abdollahi M, Fathi M, Entezami AA, Hamidi S. Synthesis of novel thermoresponsive micelles by graft copolymerization of $\mathrm{N}$-isopropylacrylamide on poly ( $\varepsilon$-caprolactone-co- $\alpha$ bromo-e-caprolactone) as macroinitiator via ATRP. J Polym Res. 2013;20:47-54.

29. Trollsas M, Lee VY, Mecerreyes D, Lowenhielm P, Moller M, Miller RD, Hedrick JL. Hydrophilic aliphatic polyesters: design, synthesis, and ring-opening polymerization of functional cyclic esters. Macromolecules 2000;33:4619-27.

30. Tian D, Dubois P, Grandfils C, Jerome R. Ring-opening polymerization of 1,4,8-trioxaspiro4.6.-9-undecanone: a new route to aliphatic polyesters bearing functional pendent groups. Macromolecules 30;1997:406-9.

31. Yao KJ, Wang JF, Zhang WJ, Lee JS, Wang CP, Chu FX, He XM, Tang CB. Degradable rosin-estercaprolactone graft copolymers. Biomacromolecules 2011;12:2171-77.

32. S RJ, Yang HW, Leu YL, Hua MY, Lee RS. Synthesis and characterization of amphiphilic functional polyesters by ringopening polymerization and click reaction. React Funct Polym. 2012;72:36-44.

33. Riva R, Schmeits $S$, Jérôme $C$, Jérôme R, Lecomte P. Combination of ring-opening polymerization and "click chemistry": toward functionalization and grafting of poly( $\varepsilon$-caprolactone). Macromolecules 2007;40:796-803.

34. Chiu FC, Wang SW, Peng KY, Lee RS. Synthesis and characterization of amphiphilic PLA-(PaN3CL-g-PBA) copolymers by ring-opening polymerization and click reaction. Polymer 2012;53:3476-84.

35. Mecerreyes D, Trollsas M, Hedrick JL. ABC BCD polymerization: A self-condensing vinyl and cyclic ester polymerization by combination free-radical and ring-opening techniques. Macromolecules 1999;32:8753-9.

36. Latere JP, Lecomte P, Dubois P, Jerome R. 2-Oxepane-1,5-dione: a precursor of a novel class of versatile semicrystalline biodegradable (co)polyesters. Macromolecules 2002;35:7857-9.

37. Liu M, Vladimirov N, Frechet JMJ. A new approach to hyperbranched polymers by ring-opening polymerization of an $A B$ monomer: 4-(2-hydroxyethyl)- $\varepsilon$-caprolactone. Macromolecules 1999;32:6881-4.

38. Lou X, Detrembleur C, Lecomte P, Jerome R. Controlled synthesis and chemical modification of unsaturated aliphatic ( $\mathrm{Co}$ )polyesters based on 6,7-dihydro-2(3H)-oxepinone. J Polym Sci Part A Polym Chem. 2002;40(14):2286-97.

39. Habnouni SE, Darcos V, Coudane J. Synthesis and ring opening polymerization of a new functional lactone, $\alpha$-iodo$\varepsilon$-caprolactone: a novel route to functionalized aliphatic polyesters. Macromol Rapid Comm. 2009;30:165-9.

40. Gautier S, Aloia V, Halleux O, Mazza M, Lecomte P, Jerome R. Amphiphilic copolymers of $\varepsilon$-caprolactone and $\gamma$-substituted $\varepsilon$-caprolactone, synthesis and functionalization of poly(D,Llactide) nanoparticles. J Biomat Sci Polym Ed. 2003;14:63-85.

41. Lou $X$, Detrembleur $C$, Lecomte $P$, Jerome R. Living ringopening (co)polymerization of 6,7-dihydro-2(5H)-oxepinone into unsaturated aliphatic polyesters. Macromolecules 2001;34:5806-11.

42. Yan JL, Zhang Y, Xiao Y, Zhang Y, Lang MD. Novel poly(e-caprolactone)s bearing amino groups: synthesis, characterization and biotinylation. React Funct Polym. 2010;70:400-7. 
43. Ciania L, Bortolussi S, Postuma L, Cansolino L, Ferrari C, Panza L, Altieri S, Ristori S. Rational design of gold nanoparticles functionalized with carboranes for application in boron neutron capture therapy. Int J Pharm. 2013;458:340-6.

44. Mecerreyes D, Miller RD, Hedrick JL, Detrembleur C, Jerome R. Ring-opening polymerization of 6-hydroxynon-8-enoic acid lactone: Novel biodegradable copolymers containing allyl pendent groups. J Polym Sci Part A Polym Chem. 2000;38(5):870-5.

45. Mahmud A, Xiong XB, Lavasanifar A. Novel self-associating poly(ethyleneoxide)-block-poly( $\varepsilon$-caprolactone) block copolymers with functional side groups on the polyester block for drug delivery. Macromolecules 2006;39:9419-28.

46. Mecerreyes D, Humes J, Miller RD, Hedrick JL, Detrembleur C, Lecomte P, Jerome R, Roman JS. First example of an unsymmetrical difunctional monomer polymerizable by two living/controlled methods. Macromol Rapid Commun. 2000;21(11):779-84.

47. Mecerreyes D, Lee V, Hawker CJ, Hedrick JL, Wursch A, Volksen W, Magbitang T, Huang E, Miller RD. A novel approach to functionalized nanoparticles: self-crosslinking of macromolecules in ultradilute solution. Adv Mater. 2001;13(3):204-8.

48. Guo ST, Qiao Y, Wang WW, He HY, Deng LD, Xing JF, Xu JQ, Liang XJ, Dong AJ. Poly(3-caprolactone)-graft-poly(2-(N,Ndimethylamino)ethylmethacrylate) nanoparticles: $\mathrm{pH}$ dependent thermo-sensitive multifunctional carriers for gene and drug delivery. J Mater Chem. 2010;20:6935-41.

49. Lin DS, Huang YY, Jiang Q, Zhang WD, Yue XY, Guo ST, Xiao P, Du Q, Xing JF, Deng LD, Liang ZC, Dong AJ. Structural contributions of blocked or grafted poly(2-dimethylaminoethyl methacrylate) on PEGylated polycaprolactone nanoparticles in siRNA delivery. Biomaterials 2011;32:8730-42.

50. van der Ende AE, Kravitz EJ, Harth E. Approach to formation of multifunctional polyester particles in controlled nanoscopic dimensions. J Am Chem Soc. 2008;130:8706-13.

51. van der Ende AE, Croce T, Hamilton S, Sathiyakumar V, Harth E. Tailored polyester nanoparticles: post-modification with dendritic transporter and targeting units via reductive amination and thiol-ene chemistry. Soft Matter 2009;5:1417-25.

52. Binder WH, Sachsenhofer R. "Click" Chemistry in polymer and material science: an update. Macromol Rapid Commun. 2008;29:952-81.

53. Rostovtsev VV, Green LG, Fokin VV, Sharpless KB. A stepwise Huisgen cycloaddition process: Copper(I)-catalyzed regioselec tive "ligation" of azides and terminal alkynes. Angew Chem Int Ed. 2002;41(14):2596-9.

54. Xiang YZ, Xiao M, Han SC, Xu SX, Cao Y, Lv ZS, Liu JF, Deng LD Dong AJ. Preparation and investigation of high solid content PTX-loaded nanoparticles dispersion via nanoprecipitation method. J Biomater Sci Polym Ed. 2014;25:1144-58.

55. Wang WW, Chang LL, Li X, Wu YL, Xing JF, Deng LD, Dong AJ. Controlled thermal gelation of poly( $\varepsilon$-caprolactone)/poly(ethylene glycol) block copolymers by modifying cyclic ether pendant groups on poly( $\varepsilon$-caprolactone). Soft Matter 2012;8:1575-83.

56. Chang LL, Deng LD, Wang WW, Lv ZS, Hu FQ Dong AJ, Zhang JH. Poly(ethyleneglycol)-b-poly( $\varepsilon$-caprolactone-co- $\gamma$-hydroxyl- $\varepsilon$ - caprolactone) bearing pendant hydroxyl groups as nanocarriers for doxorubicin delivery. Biomacromolecules 2012;13:3301-10.

57. Jin S, Gonsalves KE. A study of the mechanism of the free-radical ring-opening polymerization of 2-methylene-1,3-dioxepane. Macromolecules 1997;30:3104-6.
58. Agarwal S. Chemistry, chances and limitations of the radical ring-opening polymerization of cyclic ketene acetals for the synthesis of degradable polyesters. Polym Chem. 2010;1:953-64.

59. Agarwal S, Ren LQ. Polycaprolactone-based novel degradable ionomers by radical ring-opening polymerization of 2-methylene-1,3-dioxepane. Macromolecules 2009;42:1574-79.

60. Roberts GE, Coote ML, Heuts JPA, Morris LM, Davis TP. Radical ring-opening copolymerization of 2-methylene 1,3-dioxepane and methyl methacrylate: experiments originally designed to probe the origin of the penultimate unit effect. Macromolecules 1999;32:1332-40.

61. Sun LF, Zhuo RX, Liu ZL. Studies on the synthesis and properties of temperature responsive and biodegradable hydrogels. Macromol Biosci. 2003;3:725-8.

62. Agarwal S, Speyerer C. Degradable blends of semi-crystalline and amorphous branched poly(caprolactone): effect of microstructure on blend properties. Polymer 2010;51:1024-32.

63. Morris LM, Davis TP, Chaplin RP. An assessment of the copolymerization reaction between styrene and 2-methylene-1,3-dioxepane. Polymer 2001;42:495-500.

64. Ren LQ, Agarwal S. Synthesis, characterization, and properties evaluation of poly(N-isopropylacrylamide)-co-esters. Macromol Chem Phys. 2007;208:245-53.

65. Hedir GG, Bell CA, leong NS, Chapman E, Collins IR, O’Reilly RK, Dove AP. Functional degradable polymers by xanthate-mediated polymerization. Macromolecules 2014;47:2847-52.

66. Zhang Y, Aigner A, Agarwal S. Degradable and biocompatible poly(N,N-dimethylaminoethyl methacrylateco-caprolactone)s as DNA transfection agents. Macromol Biosci. 2013;13(9):1267-75.

67. Cui HT, Liu YD, Cheng YL, Zhang Z, Zhang PB, Chen XS, Wei Y. In vitro study of electroactive tetraaniline-containing thermosensitive hydrogels for cardiac tissue engineering. Biomacromolecules 2014;15:1115-23.

68. Undin J, Wistand AF, Albertsson AC. Adjustable degradation properties and biocompatibility of amorphous and functional poly(esteracrylate)-based materials. Biomacromolecules 2014;15:2800-7.

69. Undin J, Finne-Wistrand A, Albertsson AC. Copolymerization of 2-methylene-1,3-dioxepane and glycidyl methacrylate, a well-defined and efficient process for achieving functionalized polyesters for covalent binding of bioactive molecules. Biomacromolecules 2013;14:2095-102.

70. Jin Q, Maji S, Agarwal S. Novel amphiphilic, biodegradable, biocompatible, cross-linkable copolymers: synthesis, characterization and drug delivery applications. Polym Chem. 2012;3:2785-93.

71. Cai TJ, Chen YJ, Wang Y, Wang HB, Liu XS, Jin Q, Agarwal S, Ji J. One-step preparation of reduction-responsive biodegradable polymers as efficient intracellular drug delivery platforms. Macromol Chem Phys. 2014;215:1848-54.

72. Cai TJ, Chen YJ, Wang Y, Wang HB, Liu XS, Jin Q, Agarwal S, Ji J. Functional 2-methylene-1,3-dioxepane terpolymer: a versatile platform to construct biodegradable polymeric prodrugs for intracellular drug delivery. Polym Chem. 2014;5:4061-8.

73. Chen W, Yang HC, Wang R, Cheng R, Meng FH, Wei WX, Zhong ZY. Versatile synthesis of functional biodegradable polymers by combining ring-opening polymerization and postpolymerization modification via Michael-type addition reaction. Macromolecules 2010;43:201-7.

74. Cheng R, Wang XY, Chen W, Meng FH, Deng C, Liu HY, Zhong ZY. Biodegradable poly(3-caprolactone)-g-poly(2-hydroxyethyl 
methacrylate) graft copolymer micelles as superior nanocarriers for "smart" doxorubicin release. J Mater Chem. 2012;22:11730-8.

75. Chen W, Zou Y, Meng FH, Cheng R, Deng C, Feijen J, Zhong ZY. Glyco-nanoparticles with sheddable saccharide shells: a unique and potent platform for hepatoma-targeting delivery of anticancer drugs. Biomacromolecules 2014;15(3):900-7.
76. Galperin A, Long TJ, Garty S, Ratner BD. Synthesis and fabrication of a degradable poly( $\mathrm{N}$-isopropyl acrylamide) scaffold for tissue engineering applications. J Biomed Mater Res Part A 2013;101A:775-86.

77. Wang H, Synatschke CV, Raup A, Jérôme V, Freitag R, Agarwal S. Oligomeric dual functional antibacterial polycaprolactone. Polym Chem. 2015;5:2453-60. 